\title{
CONF-961017--18
}

\section{PROCESSING AND PROPERTIES OF FeAI-BONDED COMPOSITES}

\author{
Joachim H. Schneibel, Ramesh Subramanian, \\ Kathi B. Alexander, and Paul F. Becher \\ Metals and Ceramics Division \\ Oak Ridge National Laboratory, \\ P. O. Box 2008. Oak Ridge, TN 37831, U.S.A.
}

\begin{abstract}
A bstract
Iron aluminides, which exhibit excellent oxidation and sulfidation resistance, are thermodynamically compatible with a wide range of ceramics such as carbides, borides, oxides, and nitrides, which makes them suitable as the matrix in composites containing fine ceramic particulates. Potential applications for these new materials will be outlined. For ceramic contents varying from 30 to $60 \mathrm{vol} . \%$, composites of $\mathrm{Fe}-40$ at. \% Al with $\mathrm{WC}, \mathrm{TiC}, \mathrm{TiB}_{2}$, and $\mathrm{ZrB} 2$ were fabricated by conventional liquid phase sintering of powder mixtures. For ceramic contents from 70 to 85 vol. \%, pressureless melt infiltration was found to be a more suitable processing technique. In FeAl-60 vol.\% WC, flexure strengths of up to $1.8 \mathrm{GPa}$ were obtained, even though processing defects consisting of small oxide clusters were present. Elimination of such defects. and improvement in the interfacial bonding strength are needed to further improve the strength of these materials. Room temperature fracture toughnesses were determined by flexure testing of chevronnotched specimens. FeAl/WC and FeAl/TiC composites containing 60 vol.\% carbide particles exhibited $\mathrm{K}_{\mathrm{Q}}$ values around $20 \mathrm{MPa} \mathrm{m}{ }^{1 / 2}$. These values are similar to those found in WC/Co hard metals with similar binder volume fractions. In view of the relatively brittle behavior of monolithic iron aluminides this result is surprising. It is rationalized by the ductile necking and debonding of the thin (typically $1 \mu \mathrm{m}$ ) FeAl ligaments observed on the fracture surfaces. Slow crack growth measurements carried out in water and in dry oxygen suggest a relatively small influence of water-vapor embrittlement. It appears therefore that the mechanical properties of iron aluminides in the form of fine ligaments are quite different from their bulk properties. Further study will be needed to fully understand the relevant mechanisms. Measurements of the oxidation resistance, dry wear resistance, and thermal expansion of iron aluminide composites suggest many potential applications for these new materiais.
\end{abstract}

\section{Introduction}

Iron aluminide intermetailics such as $\mathrm{Fe}_{3} \mathrm{Al}$ and $\mathrm{FeAl}$ $(1,2)$ offer several useful features making them of interest in composite or cermet applications, in particular when compared to more common matrix alloys based on $\mathrm{Co}$ or $\mathrm{Ni}$. To start with, iron aluminides use readily available and inexpensive elements. The density of iron aluminides is relatively low. For example. the density of $\mathrm{Fe}-40$ at. $\% \mathrm{Al}$ is only $6 \mathrm{Mg} / \mathrm{m}^{3}$. Iron aluminides are also very resistant to oxidation, sulfidation, and molten nitrate salts (3). For sufficiently high $\mathrm{Al}$ concentrations $(\geq 30$ at. \%) they are not ferromagnetic, which makes them useful in die applications for magnetic materials. Lnlike $\mathrm{Co}$ or $\mathrm{Ni}$, they are not perceived to be carcinogenic. Therefore, they are likely to be more environmentally benign than those materials. In addition, Co is undesirable in radioactive environments. because it decays into reaction products with long half lives. Iron aluminides are therefore weil suited as an alternative binder for cermets used in hostile environments.

However, the successful processing of iron aluminide bonded composites requires several conditions to be met. The iron aluminides and respective ceramics have to be thermodynamically compatible not only in the solid state, but also when the iron aluminide is liquid during processing. Successful liquid phase sintering requires also that the reinforcing particulates are wetted well by liquid iron aluminides. In particular, for high ceramic volume fractions, the solubility of the ceramics in the liquid iron aluminide must be high, or excessive porosity may be encountered. While the first two requirements are met for several $\mathrm{FeAl} /$ ceramic systems, the solubilities will be seen to be relatively low. This problem may be overcome by a newly developed pressureless melt infiltration technique.

In order to provide a better understanding of this new class of iron aluminide composites and cermets, we will address the following points in this paper:

- Thermodynamic compatibility and wetting behavior
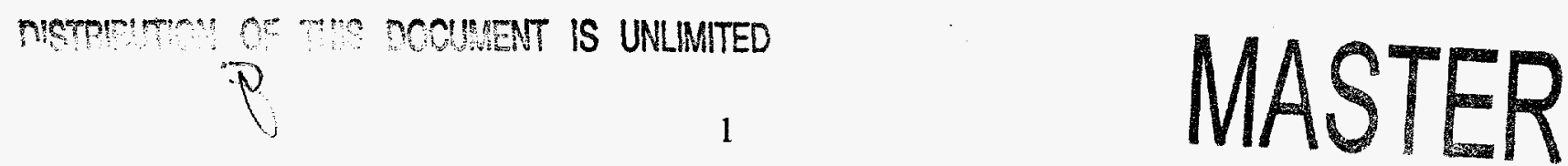


\section{DISCLAIMER}

This report was prepared as an account of work sponsored by an agency of the United States Government. Neither the United States Government nor any agency thereof, nor any of their employees, make any warranty, express or implied, or assumes any legal liabili. ty or responsibility for the accuracy, completeness, or usefulness of any information, apparatus, product, or process disclosed, or represents that its use would not infringe privately owned rights. Reference herein to any specific commercial product, process, or service by trade name, trademark, manufacturer, or otherwise does not necessarily constitute or imply its endorsement, recommendation, or favoring by the United States Government or any agency thereof. The views and opinions of authors expressed herein do not necessarily state or reflect those of the United States Government or any agency thereof. 


\section{DISCLAMMER}

Portions of this document may be illegible in electronic image products. Images are produced from the best available original document. 
- Conventional liquid phase sintering of mixtures of FeAl and ceramic powders, and the resulting mechanical properties

- Processing via a one-step pressureless melt infiltration technique and the resulting mechanical properties

- Resistance against crack growth, oxidation, and wear

- Thermal expansion.

We would also like to note that a similar, and complimentary, class of composites containing an $\mathrm{Ni3} \mathrm{Al}$ binder rather than an FeAl binder has been patented in 1990 by Tiegs and McDonald (4) and has formed the subject of several investigations (5-7).

\section{Experimental Procedure}

The iron aluminide used in this research was prealloyed, argon atomized -325 mesh powder (particle size $\leq 45 \mu \mathrm{m}$ ) with the composition $\mathrm{Fe}-40$ at. \% Al. Unless otherwise stated. the TiC and WC powders ranged from 2 to $10 \mu \mathrm{m}$ in size. The $\mathrm{TiB}_{2}$ and $\mathrm{ZrB}_{2}$ powders were -325 mesh. Metallographic sections of the boride composites showed the boride particles to be in the $5-10 \mu \mathrm{m}$ size range.

In one processing approach, ceramic composites were produced by mixing prealloyed $\mathrm{Fe}-40$ at. $\% \mathrm{Al}$ powder (Fe40Al or FeAl for brevity) with the desired ceramic powder, placing the mixture into an $\mathrm{Al}_{2} \mathrm{O}_{3}$ crucible, heating the uncovered crucible within approximately $5 \mathrm{ks}$ to a temperature of $1723 \mathrm{~K}$ in a vacuum of $10^{-4} \mathrm{~Pa}$, holding for $900 \mathrm{~s}$ at this temperature. and finally cooling in the furnace. In the infiltration approach to processing, FeAl powder was placed onto cold-pressed ceramic compacts. The infiltrations were carried out in vacuum in covered alumina crucibles with a titanium getter placed in the crucible. Typical processing conditions were $1723 \mathrm{~K}$ for $0.5 \mathrm{~h}$. Some composites were also hot isostatically pressed $(0.5 \mathrm{~h} / 1373 \mathrm{~K} / 200 \mathrm{MPa})$ after liquid phase sintering or melt infiltration. Metallographic cross sections were prepared by standard techniques and examined in optical and scanning electron microscopes (SEM). Transmission electron microscope (TEM) specimens were prepared by ion beam milling and examined by energy dispersive analysis using a thin-window detector. Bend bars for flexure strength measurements and chevron-notched specimens for fracture toughness measurements with dimensions $3 \times 4 \times 25 \mathrm{~mm}$ were fabricated by electro-discharge machining and grinding. The triangular sections in the center of the chevron-notched specimens had a width of $3 \mathrm{~mm}$ and a height of $2.5 \mathrm{~mm}$. Flexure strength and fracture toughness were measured in three-point bending with a span $\mathrm{L}$ of 20 $\mathrm{mm}$ and a crosshead speed of $10 \mu \mathrm{m} / \mathrm{s}$. The flexure strength, $\sigma_{\mathrm{f}}$, was determined from the load $\mathrm{P}_{\mathrm{f}}$ at fracture, the specimen height $h$, and the specimen width $w$ as:

$\sigma_{f}=1.5 \times\left(L P_{f}\right) /\left(w h^{2}\right)$.
The fracture toughness, $\mathrm{K}_{\mathrm{Q}}$, was determined from the energy, $\mathrm{W}$, absorbed during the tests, the area, A, swept out by the crack, and the plane strain Young's modulus, $E^{\prime}=E /(1-$ $v^{2}$ ), as:

$$
\mathrm{K}_{\mathrm{Q}}=\left[(\mathrm{W} / \mathrm{A}) \mathrm{E}^{\prime}\right]^{1 / 2}
$$

The $E^{\prime}$ values for the composites were calculated from the Young's modulus of the iron aluminide matrix, $E_{m}$, and the Young's moduli of the respective ceramic particulate. $E_{p}$, using Ravichandran's (8) eqn. (8) with a value of $v=0.2$ for Poisson's ratio:

$$
E^{\prime}=\frac{\left(c E_{p} E_{m}+E_{m}^{2}\right)(1+c)^{2}-E_{m}^{2}+E_{p} E_{m}}{\left(c E_{p}+E_{m}\right)(1+c)^{2}}
$$

where

$$
c=\left(1 / V_{p}\right)^{1 / 3}-1 \text { with } V_{p}+V_{m}=1,
$$

and $V_{p}$ and $V_{m}$ are the volume fractions of the ceramic and the iron aluminide, respectively.

\section{Thermodynamic Compatibility and Wetting}

Recent thermodynamic calculations by Misra (9) show iron aluminides to be thermodynamically compatible with a wide range of ceramics at $1273 \mathrm{~K}$. These ceramics are listed in Table I. WV was not included in Misra's calculations. Also, his calculations did not address the question whether these ceramics would be stable in liquid FeAl (the melting point of $\mathrm{Fe}-40$ at. \% Al is $1690 \mathrm{~K}$ ). To date, the compatibility of the following ceramics with liquid iron aluminide has been examined: $\mathrm{TiC}, \mathrm{WC}, \mathrm{TiB}_{2}$, and $\mathrm{ZrB} 2$. In none of these systems did SEM examinations of the microstructures obtained after liquid phase sintering suggest any reactions (10). This finding was substantiated by $\mathrm{X}$-ray diffraction (with the exception of $\mathrm{ZrB}_{2}$, where a small volume fraction of $\mathrm{FeBO}_{3}$ may have formed) (11). Consistent with the absence of significant reactions, TEM examination of a liquid phase sintered $\mathrm{FeAl} / \mathrm{TiB} 2$ composite (Fig. 1) did not show any evidence for reaction products. In the $\mathrm{TiB}_{2}$, no $\mathrm{Fe}$ or $\mathrm{Al}$ was detected, whereas the FeAl contained some B and Ti. This suggests some solubility of $\mathrm{TiB}_{2}$ in FeAl.

Thermodynamic calculations using the code ThermoCalc ${ }^{\circledR}$ were also carried out. As an example, the calculated solubility of $\mathrm{TiC}$ in liquid $\mathrm{FeAl}$ at $1723 \mathrm{~K}$ is shown in Fig. 2. The solubility is low ( $<1$ at. \%), and the $\mathrm{Ti}$ and $\mathrm{C}$ concentrations in the liquid $\mathrm{FeAl}$ depend on the stoichiometry of the $\mathrm{TiC}$, which can vary within wide limits. Similar calculations for $\mathrm{WC}(12)$ and $\mathrm{TiB}_{2}$ indicate also small solubilities $(<2$ at. \%). In summary, the calculations and experiments carried out to date for liquid FeAl containing 
Table I. Compilation of ceramics which, according to thermodynamic calculations, are stable in contact with $\mathrm{FeAl}$ at $1273 \mathrm{~K}(9)$.

\begin{tabular}{llll}
\hline Carbides & Borides & Oxides & Nitrides \\
\hline $\mathrm{HfC}$ & $\mathrm{HfB}_{2}$ & $\mathrm{Al}_{2} \mathrm{O}_{3}$ & $\mathrm{HfN}$ \\
$\mathrm{TiC}$ & $\mathrm{ScB}_{2}$ & $\mathrm{BeO}$ & \\
$\mathrm{ZrC}$ & $\mathrm{TiB}_{2}$ & $\mathrm{La}_{2} \mathrm{O}_{3}$ & \\
& $\mathrm{ZrB} 2$ & $\mathrm{Sc}_{2} \mathrm{O}_{3}$ & \\
& & $\mathrm{Y}_{2} \mathrm{O}_{3}$ & \\
\hline
\end{tabular}

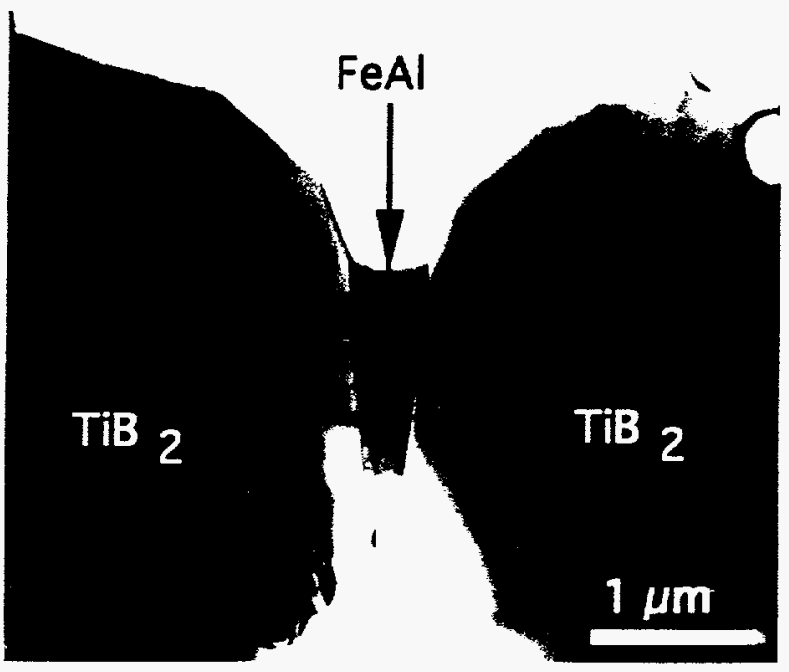

Fig. 1 - TEM micrograph of $\mathrm{Fe}-40$ at. $\% \mathrm{Al} / \mathrm{TiB} 2$ composite

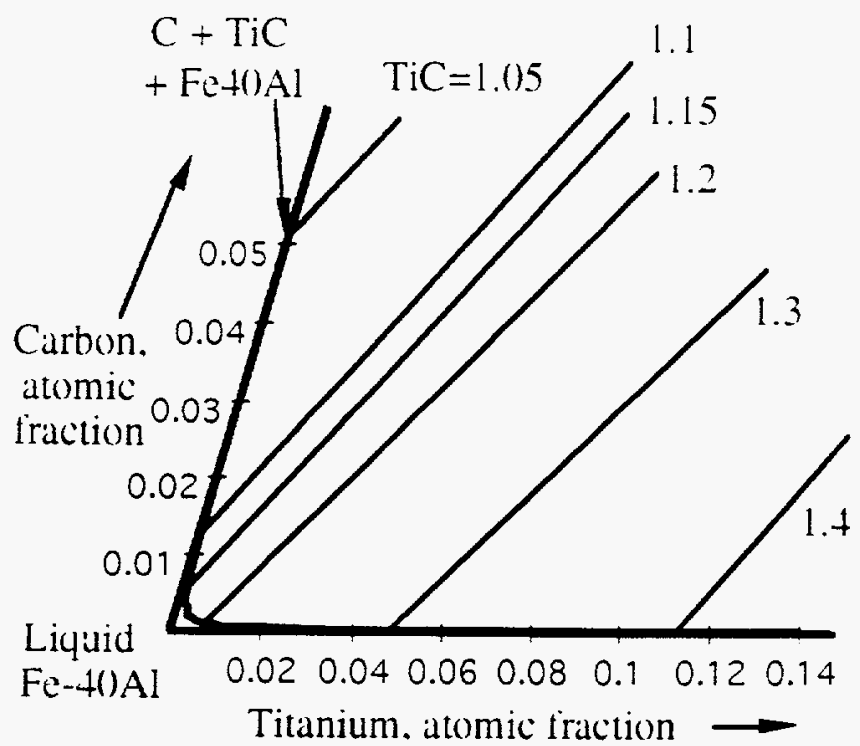

Fig. 2 - Calculated section of $\mathrm{Fe}-40$ at. \% $\mathrm{Al} / \mathrm{TiC}$ phase diagram at $1723 \mathrm{~K}$.
$\mathrm{TiC}, \mathrm{WC}, \mathrm{TiB}_{2}$, or $\mathrm{ZrB} 2$ suggest little or no reaction. and low solubilities of the ceramics in the liquid FeAl. These systems are thus quite different from the Co/WC system, in which liquid $C o$ dissolves substantial quantities (10-20 at. \%) of WC. This difference has to be taken into account in the processing of iron aluminide composites and cermets.

In addition to thermodynamic stability, the liquid phase sintering approach to the fabrication of iron aluminideceramic composites requires good wetting, i.e.. low wetting angles. In the case of the carbides and borides, this requirement seems to be fulfilled. For example, a small amount of $\mathrm{FeAl}$ was placed on a $97 \%$ dense polycrystalline TiC substrate and heated to $1723 \mathrm{~K}$ in vacuum. The wetting angle appeared to be small, typically $20^{\circ}$. The FeAl penetrated the grain boundaries of the $\mathrm{TiC}$ to a depth of approximately $100 \mu \mathrm{m}$, which is also an indication of good wetting. However, because of the grain boundary penetration, a reliable evaluation of the liquid-solid wetting angle was not possible. TiC single crystals would be required in order to measure wetting angles reliably.

\section{Processing by Liquid Phase Sintering of Mixed Powders}

The liquid phase sintering (LPS) of mixtures of prealloyed iron aluminide powders and ceramic powders is very successful as long as the ceramic volume fractions are not too high. Near-net fabrication is readily accomplished and is illustrated in Fig. 3 (11). Figure 4 shows the microstructure of an FeAl/WC composite. While almost complete densificatio: was achieved in this example. it is generally not reached : or higher WC volume fractions. For example. with 60 vol. \% WC. 98 to $99 \%$ of the theoretical density (TD) is reached, whereas only $92 \%$ TD is reached for 70 vol.\% WC (11). The hardness measurements in Fig. 5 illustrate this limitation. As soon as the ceramic volume fraction exceeds some critical value (which seems also to depend on the type and/or particle size of the ceramic), the hardness drops significantly due to excessive porosity. The porosity is due to two reasons. First, the prealloyed iron aluminide powder is relatively coarse. For example, a large FeAl particle surrounded by fine carbide particles, once liquid. will infiltrate these particles and may leave a void behind. Second, the solubility of the ceramic particles in the liquid $\mathrm{FeAl}$ is relatively low. This makes it difficult to enhance the particle packing by dissolving material away from touching carbides. This limitation might in principle be overcome by increasing the processing temperature or the sintering time. However, Al tends to evaporate from liquid $\mathrm{FeAl}$ held in vacuum, resulting in a gradual shift of the iron aluminide composition to more iron-rich compositions (11). 


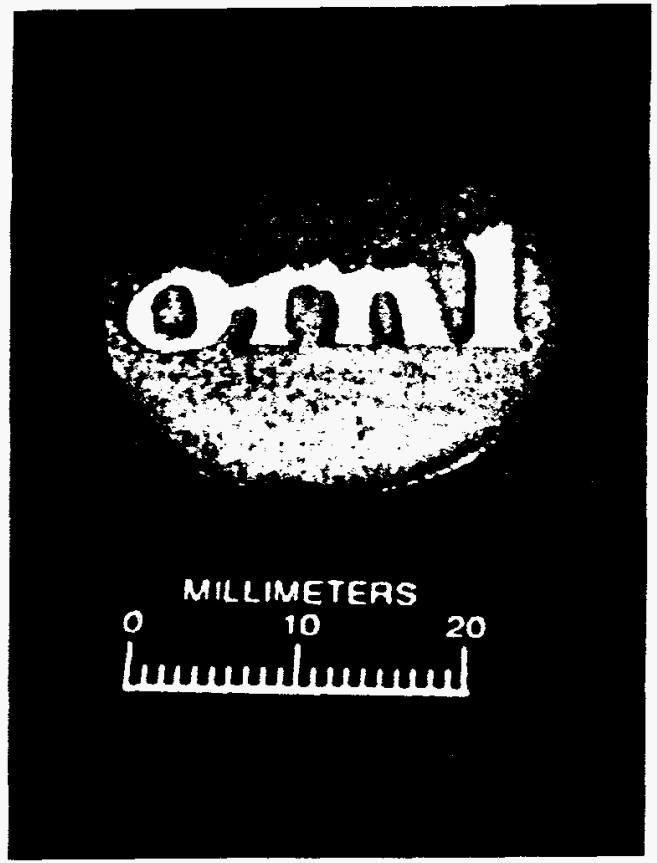

Fig. 3 - Near-net shaped $\mathrm{Fe}-40$ at. $\% \mathrm{Al} / 50$ vol. $\% \mathrm{ZrB} 2$ iron aluminide composite.

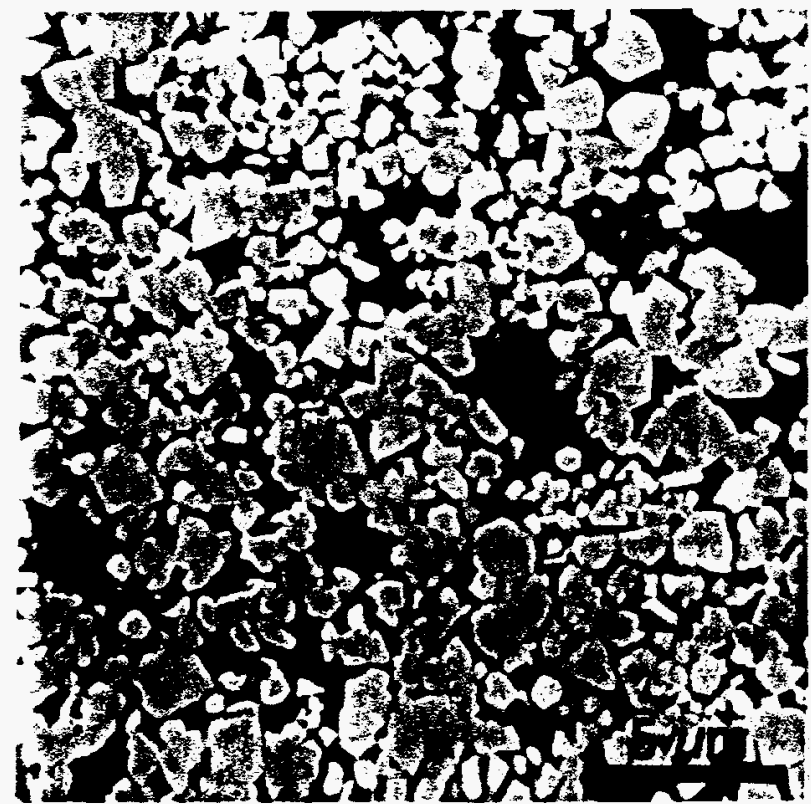

Fig. 4 - SEM micrograph of a metallographic section through $\mathrm{Fe}-40$ at. $\% \mathrm{Al} / 60$ vol. $\% \mathrm{WC}$ fabricated by liquid phase sintering of mixed powders.

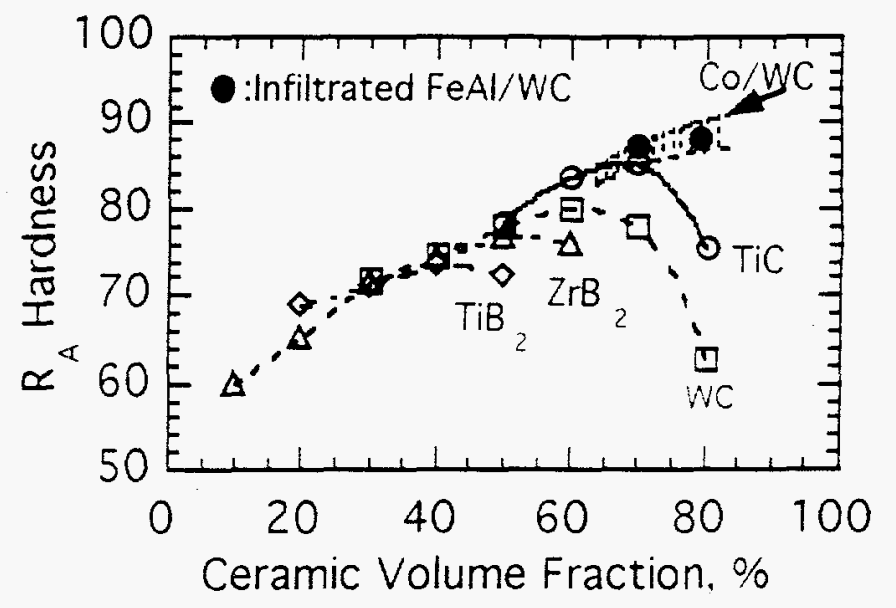

Fig. 5 - Rockwell A hardnesses of composites consisting of $\mathrm{Fe}-40$ at. \% $\mathrm{Al}$ and $\mathrm{TiC}, \mathrm{WC}$. TiB2, or $\mathrm{ZrB} 2$. A scatterband depicts the hardnesses of WC/Co materials. Unless indicated otherwise, the materials were processed via liquid phase sintering of mixed powders.

Other processing issues in the LPS of mixed powders concern the reproducibility of microstructure and properties. the presence of residual flaws, and the effect of heat treatment. Figure 6 illustrates the three-point flexure strengths of $\mathrm{FeAl} / \mathrm{WC}$ composites. Nominally identical processing by LPS does not guarantee identical strengths: the two bar clusters annotated LPS on the left-hand side of the graph show quite different flexure strengths. In an attempt to remove any residual porosity, additional consolidation by hot isostatic pressing (LPS +HIP) was carried out. This resulted in degradation of the average flexure strength. Although one bend bar exhibited a high strength close to $1800 \mathrm{MPa}$; the other specimens were much weaker. The large scatter in the data indicates a wide spread in the flaw size distributions of the specimens. Interestingly, when the LPS and HIP processing was followed by an anneal for 1 day at $773 \mathrm{~K}$ in vacuum, the scatter was reduced, 2 out of 5 bars exhibited a flexure strength close to $1800 \mathrm{MPa}$, and the average strength increased to $(1747 \pm 56) \mathrm{MPa}$. This can be understood as follows: the HIP schedule involved a fairly fast cool from the $1373 \mathrm{~K}$ HIPing temperature (about 1000 s). Since iron aluminides are known to contain large concentrations of thermal vacancies (e.g., 1 at. \% at $1273 \mathrm{~K}$ ), it is likely that a substantial concentration of vacancies was frozen in during the fast cool-down. These vacancies increase the yield strength, and reduce the fracture toughness (13). This could very well lead to a reduction in the flexure strength due to increased flaw sensitivity. The subsequent anneal at $773 \mathrm{~K}$ most likely reduced the yield strength of the FeAl matrix, while increasing its ductility and fracture 
toughness. The expected improvement in the flaw tolerance of the composite may be responsible for the improved flexure strengths and decrease in the scatter.

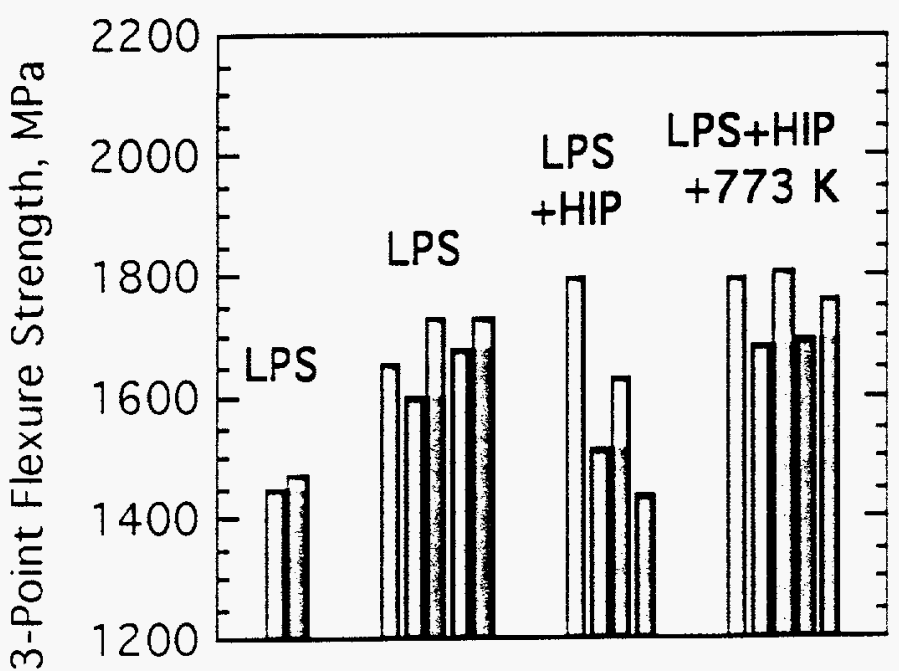

Fig.6 - Flexure strength of $\mathrm{Fe}-40$ at. $\% \mathrm{Al} / 60$ vol. $\%$ WC composites. $\mathrm{LPS}=$ liquid phase sintering; $\mathrm{HIP}=$ hot isostatic pressing; $773 \mathrm{~K}$ refers to a 1 day anneal at this temperature.

As has been noted before (12), the FeAl/WC composites processed by LPS contain clusters of oxide inclusions which may limit their strength. These clusters are also found after HIPing. For example. Fig. 7 shows a cluster of aluminum oxide particles found on a fracture surface of HIPed $\mathrm{FeAl} / \mathrm{WC}$. This illustrates the difficulty in using aluminaforming matrix materials such as $\mathrm{FeAl}$ as binders in cermets: whereas alumina formation on the surface of finished parts is desirable in service. it is a disadvantage during processing.

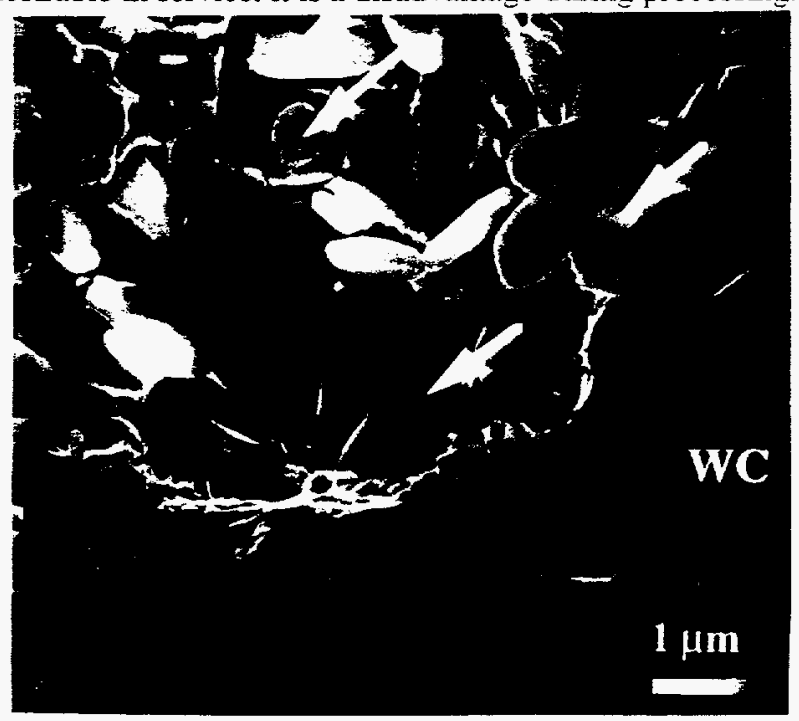

Fig. 7 - Cluster of aluminum oxide inclusions on fracture surface of $\mathrm{Fe}-40$ at. $\% \mathrm{Al} / 60$ vol.\% WC material. Some $\mathrm{Al}_{2} \mathrm{O}_{3}$ inclusions are indicated by arrows.
In recent work by Thomas (14), FeAl/WC cermets were fabricated using much more elaborate powder-metallurgical techniques than those employed in the present ork. Prealloyed $\mathrm{Fe}-40$ at. $\% \mathrm{Al}$ powder was blended with $6 \mathrm{i}$. ol. \% ( $80 \mathrm{wt} \%$ ) WC powder in isopropanol, compacted in uniaxial compression, cold isostatic pressed. liquid phase sintered in vacuum, and. in the last step, gas-pressure sintered (1.9 $\mathrm{MPa} / 1768 \mathrm{~K}$ ). In spite of the involved processing. these materials contained residual pores. The nature of these pores was not further identified. In spite of the possibility of internal pores. the 4-point flexure strength of this material reached a high value of $1800 \mathrm{MPa}$. which is similar to the values obtained in our three-point tests.

\section{Processing by Pressureless Melt Infiltration}

As pointed out before. the relatively low solubility of ceramics in $\mathrm{FeAl}$ is a limitation in the processing of iron aluminide composites. Subramanian et al. (15) recently devised a one-step pressureless infiltration technique to overcome this limitation. The process is shown schematically in Fig. 8. A TiC preform is prepared by coldpressing and FeAl powder is placed on top of it. Once the iron aluminide becomes liquid during heat-up in a vacuum furnace, it infiltrates the TiC preform completely. Because this process avoids the incorporation of large $\mathrm{FeAl}$ particles in the preform (which may give rise to porosity), and because considerable particle rearrangement may occur as the liquid penetrates the preform. composites with very high ceramic volume fractions may be fabricated in this manner. Figure 9 illustrates the microstructure of a $\mathrm{FeAl} / \mathrm{TiC}$ composite processed in this way, with a nominal $\mathrm{TiC}$ volume fraction of $80 \%$. Such composites exhibit typically $99 \%$ of the theoretical density. The flexure strengths for such high ceramic volume fractions are somewhat lower than those for 60 vol. \%. For example. Subramanian et al. (15-17) obtained flexure strengths of 1030 and $1200 \mathrm{MPa}$ in FeAl composites containing $70 \mathrm{vol} . \% \mathrm{TiC}$ or WC, respectively. However, the hardnesses of these materials are very high and fall in the range of Co-bonded WC (see Fig. 5). Almost fully dense $\mathrm{FeAl} / \mathrm{TiB}_{2}$ composites containing $70 \mathrm{vol} . \% \mathrm{TiB}_{2}$ have also been fabricated and exhibit Rockwell $A$ hardnesses in the vicinity of 90 .

The particular melt-infiltration technique employed here has several attractive features. First, a separate sintering step to make a preform prior to infiltration is not required: the composite is fabricated in a single heating cycle. Second, the infiltration is presumably accompanied by less oxide formation than the sintering of mixed powders, since the iron aluminide advances through the preform as a liquid front. 


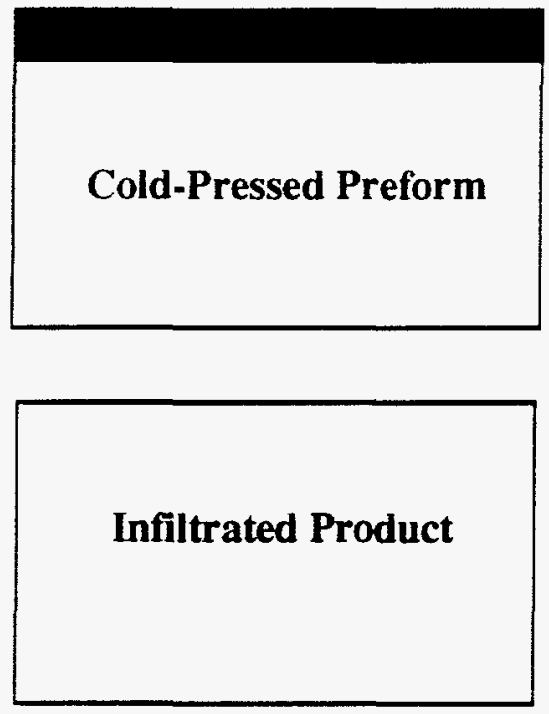

Fig. 8 - Schematic representation of ne-step pressureless melt infiltration technique.

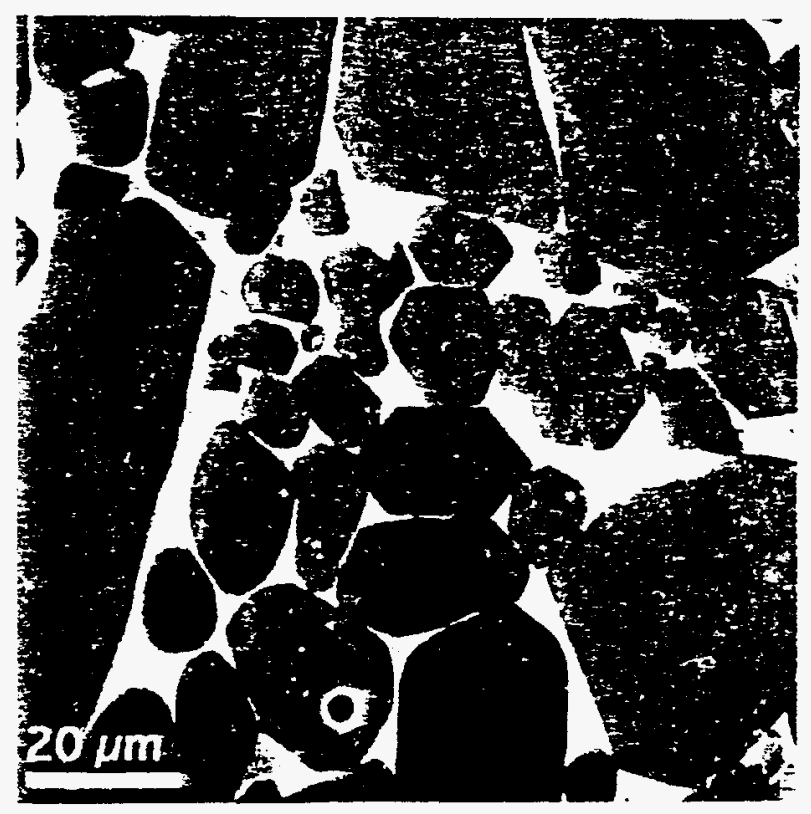

Fig. 9 - SEM micrograph of melt-infiltrated Fe-40 at. $c_{c}$ $\mathrm{Al} / 80 \mathrm{vol} . \% \mathrm{TiC}$.

\section{Crack Growth Resistance}

Figure 10 shows the fracture toughnesses of $\mathrm{FeAl} / \mathrm{WC}$ composites containing different WC volume fractions (10). As expected, the fracture toughness decreases as the WC volume fraction increases. The literature on cemented carbides $(18.19)$ suggests that the toughening is to a large extent determined by the ductile deformation and energy absorption of ligaments of the binder phase. For a given volume fraction, the toughening depends on the plastic parameters of the matrix such as yield strength. work hardening, ultimate tensile strength. and strain to fracture. Iron aluminides with the B2 structure are usually considered to suffer from low ductility. Their ductility in air rarely exceeds $10 \%$. For a given volume fraction of ceramic particulates, one would therefore expect the toughening due to iron aluminides to be significantly less than that due to cobalt. Approximate values for the fracture toughnesses of WC/Co with different Co volume fractions were taken from the data of Sigl et al. (18) and the compilation of Ravichandran et al. (19), which lists the results of many different authors using different testing techniques. These values were plotted in Fig. 10. Surprisingly, Fig. 10 shows that the fracture toughnesses of $\mathrm{FeAl}$ composites and $\mathrm{WC} / \mathrm{Co}$ are of comparable magnitude. Also. fracture surface observations show that the $\mathrm{FeAl}$ matrix undergoes debonding accompanied by extensive plastic deformation as illustrated in Fig. 11. While the high ductility is in qualitative agreement with the high fracture toughnesses. the interfacial debonding suggests limited interfacial strength. The interfacial strength may thus limit the flexure strength of iron aluminide-bonded cermets.

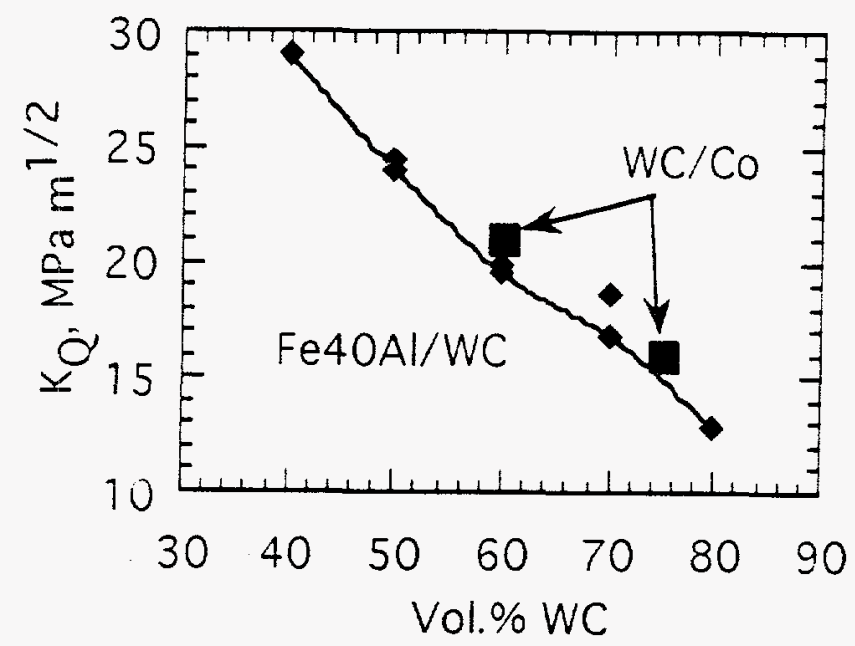

Fig. 10. Fracture toughness of FeAl/WC composites as a function of the WC volume fraction. Representative WC/Co values are indicated.

Another surprising result is shown in Fig. 12. Slow crack growth measurements were carried out with an Fe40Al$60 \mathrm{vol} . \% \mathrm{TiC}$ composite in either water or in dry oxygen. Iron aluminides are very sensitive to water vapor as first discovered by Liu et al. (20). Lynch and Heldt (21) report a tensile ductility in dry oxygen or in vacuum of $9 \%$, which decreases to $1 \%$ for a relative humidity of $100 \%$. Although Fig. 12 shows a decrease in the energy absorbed during the slow fracture of a chevron-notched specimen in water as compared to dry oxygen, this decrease (i.e.. the 


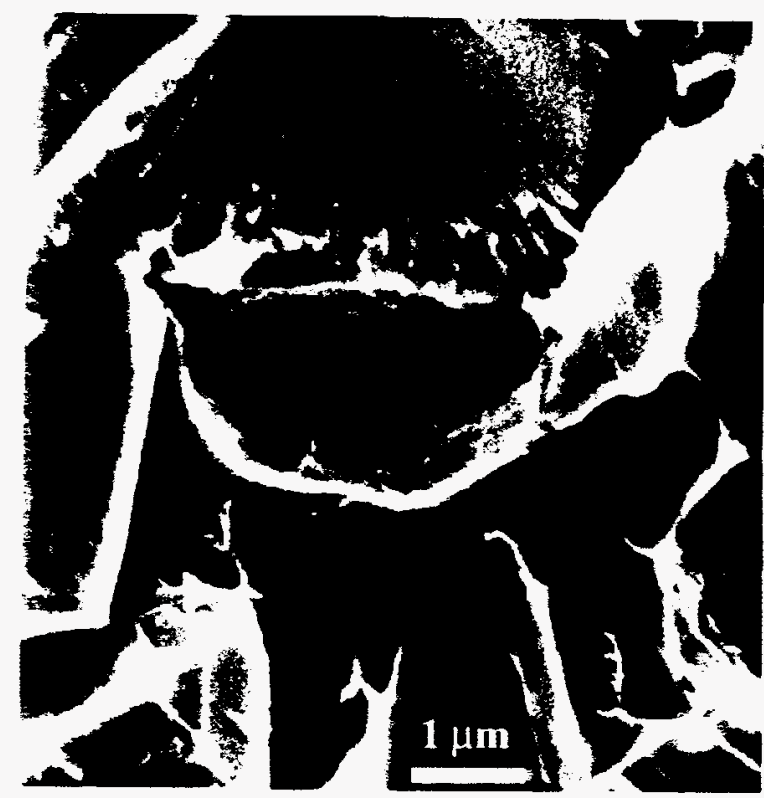

Fig. 11. Ductile deformation and interfacial debonding of iron aluminide ligament on $\mathrm{Fe}-40$ at. $\% \mathrm{Al} / 60 \mathrm{vol} . \% \mathrm{WC}$ fracture surface. This particular composite was fabricated from WC with a particle size of $29 \mu \mathrm{m}$.

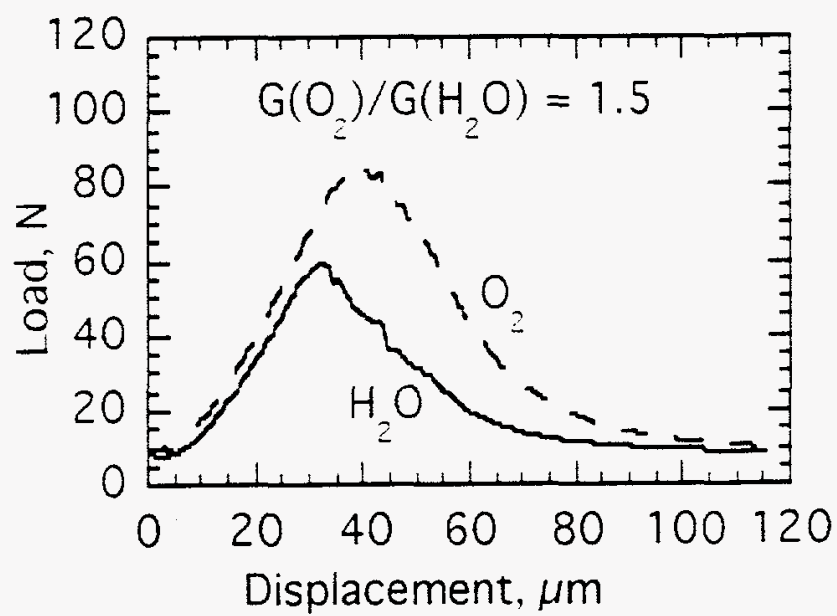

Fig. 12. Load-displacement curves for the 3-point bending of chevron-notched $\mathrm{Fe}-40$ at. \% Al/60 vol.\% TiC composites in either dry oxygen or water at room temperature. The crack propagation rate was approximately $0.5 \mu \mathrm{m} / \mathrm{s}$.

difference in the areas included under the respective curves) is approximately $50 \%$, which is relatively small. For comparison, the energy absorbed in (humid) air during slow crack growth of monolithic iron aluminides may be lower by more than a factor of four than that absorbed during fast crack growth (where water vapor embrittlement is suppressed due to kinetic reasons) (22). This suggests the possibility that $\mathrm{FeAl}$ in the form of thin ligaments may not be as sensitive to humidity embrittlement as macroscopic. monolithic FeAl. More research will be needed to substantiate the possibility that the environmental embrittlement of iron aluminides is alleviated in iron aluminide composites.

\section{Oxidation Resistance}

Since high oxidation resistance is one of the merits of iron aluminides, it is obviously of interest to find out to what extent this oxidation resistance translates into the composites. WC/Co, the most commonly used hard metal. was chosen as a basis for comparison. Figure 13 shows indeed that the oxidation resistance of the iron aluminide matrix leads to a high oxidation resistance of the composites as compared to WC/Co.

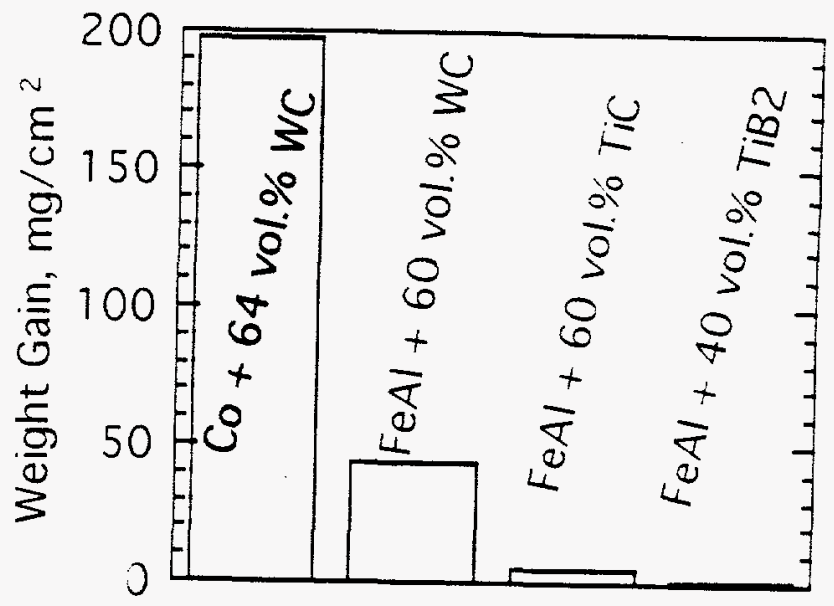

Fig. 13. Comparison of the oxidation behavior of $\mathrm{WC} / \mathrm{Co}$. $\mathrm{FeAl} / \mathrm{WC}$. FeAl/TiC, and $\mathrm{FeAl} / \mathrm{TiB}_{2}$ (oxidation in air for 1 day at $1173 \mathrm{~K}$ ).

\section{Wear Behavior}

A preliminary study of the dry wear resistance of $\mathrm{FeAl} / \mathrm{TiC}$ was carried out. In Table II. the wear losses are compared against those of $\mathrm{WC} / \mathrm{Co}$ with a similar volume fraction of $\mathrm{Co}$. The mass loss of the $\mathrm{FeAl} / \mathrm{TiC}$ composite is much lower than that of WC/Co. However, because of the high density of WC, the situation is reversed for the volume losses. Nevertheless it can be stated that iron aluminide bonded composites exhibit a high resistance to dry wear.

Table II. Dry wear test results according to ASTM G65A (dry sand/rubber wheel)

\begin{tabular}{ccc}
\hline & $\begin{array}{c}\mathrm{Fe}-40 \text { at. \% } \\
80 \text { vol. } \% \mathrm{TiC}\end{array}$ & $\begin{array}{c}\mathrm{Co} / 80 \text { vol.\% WC } \\
\text { (WC-13wt\%Co) }\end{array}$ \\
\hline Density, $\mathrm{Mg} / \mathrm{m}^{3}$ & 5.16 & 14.2 \\
Mass Loss. $\mathrm{g}$ & 0.0501 & 0.0931 \\
Volume loss. & 9.7 & 6.6 \\
$\mathrm{~mm}^{3}$ & & \\
\hline
\end{tabular}




\section{Thermal Expansion}

The thermal expansion behavior of iron aluminides has been determined by Porter and Maziasz (23). Figure 14 shows the thermal expansion of a monolithic iron aluminide to be higher than that of iron. Also shown in this plot is the thermal expansion of TiC. Clearly, the thermal expansion of an $\mathrm{FeAl} / 60$ vol. \% $\mathrm{TiC}$ composite lies between two extremes. namely, that of $\mathrm{FeAl}$ on one hand, and that of $\mathrm{TiC}$ on the other. A cursory inspection shows that the CTE of the composite follows roughly a rule of mixtures. By adjusting the $\mathrm{TiC}$ volume fraction, it is in principle possible to adjust the coefficient of thermal expansion (CTE) of an FeAl/TiC or FeAI/WC composite to that of a steel. This might be a useful property when considering, for example. wear-resistant sleeves in cast iron.

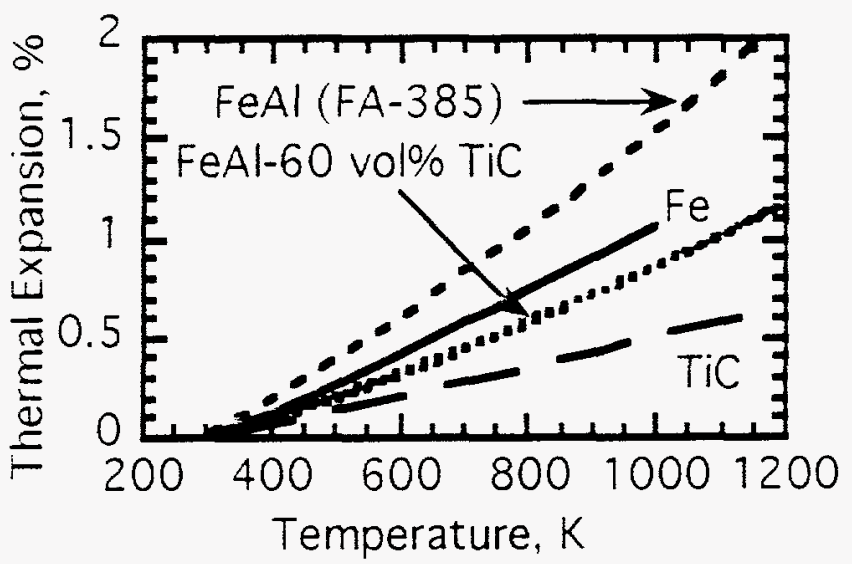

Fig. 14. Comparison between the thermal expansions of $\mathrm{Fe}$ and $\mathrm{FeAl}$ (FA-385 $=\mathrm{Fe}-36.5$ at. \% $\mathrm{Al}$ with minor alloying additions), TiC. and FeAl/60 vol.c TiC.

\section{Potential Applications}

The new class of iron aluminide bonded composites or cermets reviewed in this work may be useful in a variety of wear applications. Of particular relevance are wear applications in erosive and corrosive environments, where the resistance of iron aluminides against oxidation, sulfidation, and molten salts can be exploited. Applications of interest include various types of dies, bearing sleeves (where CTE matching might be advantageous), mechanical face seals. and impellers for slurry pumps. Since $\mathrm{TiB}_{2}$ is of interest in molten aluminum applications, the $\mathrm{FeAl} / \mathrm{TiB}_{2}$ system should be considered for the handling of molten or semi-solid aluminum. Other features relevant for future applications are of course the potentially low price of iron aluminides, their low mass density, and, in comparison to $\mathrm{Co}, \mathrm{Ni}$, or $\mathrm{Cr}$, their greater environmental friendliness.

\section{Conclusion}

We have shown that ceramics. such as $\mathrm{TiB}_{2}, \mathrm{ZrB} 2$, TiC. and WC. may be liquid phase sintered or meit-infiltrated with iron aluminide intermetallics, and are sufficiently stable thermodynamically in contact with iron aluminides. Neartheoretical densities have been found for ceramic volume fractions up to $85 \%$. In the FeAl/WC system, flexure strengths and fracture toughness values on the order of 1800 $\mathrm{MPa}$ and $20 \mathrm{MPa} \mathrm{m}^{1 / 2}$ were achieved for a $\mathrm{WC}$ volume fraction of $60 \%$. The flexure strengths may be limited by clusters of small oxide inclusions and insufficient interfacial bonding between the FeAl matrix and the ceramic particulates. Whereas HIPed specimens showed significant scatter in their flexure properties. a subsequent low temperature anneal $(773 \mathrm{~K}$ ) improved the strength. while at the same time reducing the scatter. This is attributed to the softening of the iron aluminide matrix and the associated lower flaw sens...ivity. In view of the relative brittleness of monolithic iron aluminides, the fracture tougnnesses of iron aluminide composites are surprisingly high. Also. the water vapor embrittlement is not as severe as might be expected. This may be due to the fact that the iron aluminide occurs in the composites in the form of very fine ligaments. Other properties such as oxidation resistance. wear resistance. and thermal expansion have been examined and make this new class of iron aluminide composites of interest in a variety of applications.

\section{Acknowledgements}

This research was sponsored by the Division of Materials Sciences. and the Assistant Secretary for Energy Efficiency and Renewable Energy, Office of Industrial Technologies, Advanced Industrial Materiais (AIM) Program. L.S. Department of Energy, under contract number DEAC05-96OR22464 with Oak Ridge National Laboratory. managed by Lockheed Martin Energy Research Corporation. This research was also supported in part by an appointment to the ORNL Post-Doctoral Research Associates Program administered jointly by the ORISE and ORNL.

\section{References}

1 Horton. J. A., I. Baker. S. Hanada. R. D. Noebe, R. D., D. S. Schwartz, eds., High Temperature Ordered Intermetallic Alloys VI, Vol. 364. MRS, Boston. MA. 1995.

2 Schneibel. J. H., M. A. Crimp, eds.. Processing, Properies, and Applications of Iron Aluminides. TMS. Warrendale, PA. 1994.

3 Tortorelli. P. F., and J. H. DeVan. in Processing. Properies, and Applications of Iron Aluminides. J. H. Schneibel and M. A. Crimp. eds., TMS. Warrendale. PA. 1994. pp. 257-270. 
Tiegs, T. N. and R. R. McDonald. Ductile Ni3Al Alloys as Bonding Agents for Ceramic Material, U.S. Patent 4,919,718, 1990.

5 Tiegs, T. N., P. A. Menchhofer, K. P. Plucknett, K. B. Alexander, P. F. Becher, and S. B. Waters, in $P / M$ in Aerospace, Defense and Demanding Applications 1995, ed. F. H. Froes, Metal Powder Industries Federation. NJ, 1995, pp. 211-218.

6 Tiegs, T. N., K. B. Alexander, K. P. Plucknett, P. A. Menchhofer, P. F. Becher. and S. B. Waters, Mater. Sci. Eng. A209, 243-247 (1996).

7 Plucknett, K. P., T. N. Tiegs, K. B. Alexander, P. F. Becher, J. H. Schneibel. S. B. Waters and P. A. Menchhofer, in Advanced Ceramics for Structural and Tribological Applications, eds. T. Troczynski, and H. M. Hawthorne, CIM, Vancouver, British Columbia. Canada. 1996. p. $511-520$.

8 Ravichandran. K. S., Acta Metall. Mater. 42 (1994) 1113-23.

9 Misra. A. K.. Metall. Trans. A 21A (1990) $441-46$.

10 Schneibel. J. H.. Carmichael. C. A., in Sintering Technology, eds. R. M. German. G. L. Messing, and R. G. Cornwall, Marcel Dekker, New York, 1996. pp. 253-60.

11 Schneibel. J. H., C. A. Carmichael. E. D. Specht. and $R$. Subramanian, accepted for publication in Intermetallics. 1996.

12 Schneibel. J. H.. and R. Subramanian. in "Advances in Powder Metallurgy \& Particulate Materials." Proc. 1996 World Congress on Powder Metallurgy \& Particulate Materials. June 16-21, Washington. D.C., Metal Powder Industries Federation. New Jersey, Vol. 5, pp. 16-167 to 16-175. 1996.

13 Schneibel, J. H., and P. J. Maziasz. in Processing, Properties, and Applications of Iron Aluminides, J. H. Schneibel and M. A. Crimp, eds., TMS, Pittsburgh, 1994, pp. 183-92.

14 Thomas, C. B., Processing, Mechanical Behavior, and Microstructural Characterization of Liquid Phase Sintered Intermetallic Bonded Composites, Master of Science Thesis. University of Tennessee, 1996.

15 Subramanian, R., J. H. Schneibel, K. B. Alexander, and K. P. Plucknett, Scr. Mater. 35, 583-588 (1996).

16 Subramanian, R., J. H. Schneibel, and K. B. Alexander, in "Advances in Powder Metallurgy \& Particulate Materials," Proc. 1996 World Congress on Powder Metallurgy \& Particulate Materials, June 16-21, Washington. D.C., Metal Powder Industries Federation. New Jersey, Vol. 5, pp. 16-159 to 16165, 1996.

17 Subramanian, R. and J. H. Schneibel, accepted for publication in Intermetallics.

18 Sigl, L. S., and H. F. Fischmeister, Acta Metall. 36. $887-97$ (1988).
19 Ravichandran, K. S., Acta Metall Mater. 42. 143150 (1994).

20 Liu, C. T.. E. H. Lee, C. G. McKamey, Scr. Metall., 23. 875-80 (1989).

21 Lynch, R. L., M. Harburn, L. Maucione. and L. A. Heldt. Scr. Metall. Mater. 30. 1157-1160 (1994).

22 J. H. Schneibel and E. D. Specht. Scripta Met.ll. Mater. 31. 1737-42 (1994).

23 Porter, W. D., and P. J. Maziasz. Scr. Metall. Mater. 29. $1043-1048$ (1993). 